\title{
Efficacy of fortification of cow's milk as a dietary strategy to increase dietary vitamin D intakes
}

\author{
R. R. Weir ${ }^{1}$, M. Johnston ${ }^{2}$, C. Lowis ${ }^{2}$, A. M. Fearon ${ }^{3}$, J. A. M. Beattie ${ }^{3}$, J. J. Strain ${ }^{1}$ \\ and L. K. Pourshahidi ${ }^{1}$ \\ ${ }^{1}$ Northern Ireland Centre for Food and Health (NICHE), University of Ulster, Coleraine, BT52 1SA, UK, ${ }^{2}$ Dairy \\ Council for Northern Ireland, Shaftesbury House, Edgewater Office Park, Belfast, BT3 9JQ, UK and ${ }^{3}$ Agri-Food and \\ Biosciences Institute (AFBI), Belfast, BT9 5PX, UK
}

The majority of vitamin D required by humans is derived by ultraviolet (UV) radiation of the 7-dehydrocholesterol in the skin ${ }^{(1)}$. Vitamin D can also be obtained from the diet, and these sources of vitamin D are of particular importance here in the UK and Ireland as a number of factors, including age, skin pigmentation, clothing and the use of sun protection, and geographical location, negatively influence the skin's ability to synthesise the vitamin ${ }^{(2)}$. Milk is a source of naturally occurring vitamin D (albeit providing a small contribution); the vitamin D content of whole, semi-skimmed and skimmed milk is currently listed as $0.03 \mu \mathrm{g}, 0.01 \mu \mathrm{g}$ and trace per $100 \mathrm{~g}$, respectively ${ }^{(1)}$. Numerous studies have reported the effectiveness of dairy fortification as a strategy to increase dietary vitamin D intakes at the population level ${ }^{(3,4)}$. The aim of this study was to use population level dietary data to simulate how fortified cow's milk could contribute to total dietary vitamin D intake using a dietary modelling approach.

Data from the National Diet and Nutrition Survey (NDNS) rolling programme (2008-2011) were obtained from the UK Data Service $^{(5)}$. A total of 12,239 recorded diary days $(n 3,073)$ were available for analysis. The vitamin $\mathrm{D}$ content of whole, semi-skimmed, skimmed and $1 \%$ fat milk was then manipulated to apply three incremental levels of fortification $(1 \mu \mathrm{g}, 1.5 \mu \mathrm{g}$ and $2 \mu \mathrm{g}$ per $100 \mathrm{ml})$, and the effect on total vitamin D intake was investigated in all milk consumers.

A total of $82.5 \%$ diary days reported an intake of cow's milk, with intakes of consumption ranging from $2-1,764 \mathrm{ml}$ with a mean intake of 202 (SD 180) $\mathrm{ml} / \mathrm{d}$. While semi-skimmed milk proved the most popular type of milk among consumers (51\% of diary days), the mean volume of whole milk consumed was higher, compared to that of semi-skimmed milk (249.7(SD 207) vs.187(SD 162.1 ml/d; $P<0.001)$. As a result, the simulated fortification of whole milk showed the greatest increase in total vitamin D intake.

\begin{tabular}{|c|c|c|c|c|c|c|c|c|}
\hline & \multicolumn{8}{|c|}{ Total vitamin D intake $(\mu \mathrm{g} / \mathrm{d})$} \\
\hline & \multicolumn{8}{|c|}{ Fortification levels of milk } \\
\hline & \multicolumn{2}{|c|}{$0 \mu \mathrm{g} / 100 \mathrm{ml}^{*}$} & \multicolumn{2}{|c|}{$1 \mu \mathrm{g} / 100 \mathrm{ml}$} & \multicolumn{2}{|c|}{$1.5 \mu \mathrm{g} / 100 \mathrm{ml}$} & \multicolumn{2}{|c|}{$2 \mu \mathrm{g} / 100 \mathrm{ml}$} \\
\hline & Median & Percentiles & Median & Percentiles & Median & Percentiles & Median & Percentiles \\
\hline Whole milk & $1.86^{\mathrm{a}}$ & $0.91-3.39$ & $4.46^{\mathrm{b}}$ & $2.72-6.84$ & $5.63^{\mathrm{c}}$ & $3.37-8.52$ & $6.73^{\mathrm{d}}$ & $4.02-10.39$ \\
\hline Semi-skimmed milk & $2.13^{\mathrm{a}}$ & $1.08-4.03$ & $4.06^{\mathrm{b}}$ & $2.59-6.44$ & $4.91^{\mathrm{c}}$ & $3.14-7.74$ & $5.75^{\mathrm{d}}$ & $3.68-9.04$ \\
\hline Skimmed milk & $2.61^{\mathrm{a}}$ & $1.12-5.11$ & $4.32^{\mathrm{b}}$ & $2.48-7.06$ & $5.20^{\mathrm{c}}$ & $2.94-8.28$ & $5.98^{\mathrm{d}}$ & $3.37-9.47$ \\
\hline $1 \%$ fat milk & $4.12^{\mathrm{a}}$ & $2.69-7.18$ & $2.69^{\mathrm{b}}$ & $4.12-7.18$ & $5.25^{\mathrm{c}}$ & $3.14-7.94$ & $6.47^{\mathrm{d}}$ & $3.55-9.07$ \\
\hline
\end{tabular}

* Vitamin D content of milk as listed in the McCance and Widdowson ${ }^{(1)}$.

Percentiles $\left(25^{\text {th }}, 75^{\text {th }}\right)$.

a,b,c,d values within a row with different superscript letters represent significance $(P<0.001$, Friedman Test and Wilcoxon Signed Rank Test)

Results show that fortification of UK cow's milk with vitamin D, at concentrations similar to that applied in the US/Canada (approximately $1 \mu \mathrm{g} / 100 \mathrm{ml}$ ), would significantly increase consumer's vitamin D intake. Such fortification would therefore be an effective strategy to increase vitamin D intakes, and subsequently improve the vitamin D status at the population level. While this study has focused solely on the effect of vitamin D fortification of cow's milk, more research is needed to investigate the impact of such fortification on the vitamin D content of other dairy products and their contributions to consumer's dietary vitamin D intakes.

1. McCance RA \& Widdowson E (2002) In McCance and Widdowson's The Composition of Foods, 6th Edition. Cambridge: Royal Society of Chemistry.

2. Hagenau T, Vest R, Gissel TN et al. (2009) OsteoporisInt 20, 133-40.

3. Calvo MS, Whiting SJ, Barton CN (2004) Am J ClinNutr 80, 1710S-6S.

4. Kruger MC, Schollum LM, Kuhn-Sherlock B et al. (2010) Bone 46, 759-67.

5. UK Data Service http://discover.ukdataservice.ac.uk/ 